\title{
Correction to: Acceptability, Feasibility, and Preliminary Effectiveness of Group Cognitive Processing Therapy with Female Adolescent Survivors of Commercial Sexual Exploitation in Cambodia
}

\author{
Tracy A. Clemans ${ }^{1} \cdot$ Kirsi L. White ${ }^{2}$. Dianna Fuessel-Herrmann ${ }^{3} \cdot$ Craig J. Bryan $^{4} \cdot$ Patricia A. Resick $^{5}$
}

Published online: 15 October 2021

(c) Springer Nature Switzerland AG 2021

Correction to: Journal of Child \& Adolescent Trauma https://doi.org/10.1007/s40653-021-00405-6

The original article contains incorrect Figs. 1, 2, and 3. The correct ones are shown below:

Publisher's Note Springer Nature remains neutral with regard to jurisdictional claims in published maps and institutional affiliations.

The original article can be found online at https://doi.org/10.1007/ s40653-021-00405-6.

Tracy A. Clemans

tracy.clemans@uky.edu

1 The Center On Trauma and Children, University of Kentucky College of Medicine, 3470 Blazer Parkway, Suite 100, Lexington, KY 40509, USA

2 Catholic University of America, Washington, USA

3 VA Salt Lake City Health Care System, Salt Lake City, USA

4 The Ohio State University College of Medicine, Columbus, USA

5 Department of Psychiatry and Behavioral Sciences, Duke, Health, Durham, USA 
Fig. 1 Change in PTSD symptom severity over time (CPSS)

Fig. 2 Change in PTSD symptom severity over time (UCLA PTSD-RI)

Fig. 3 Change in depression symptoms over time (PHQ-A)
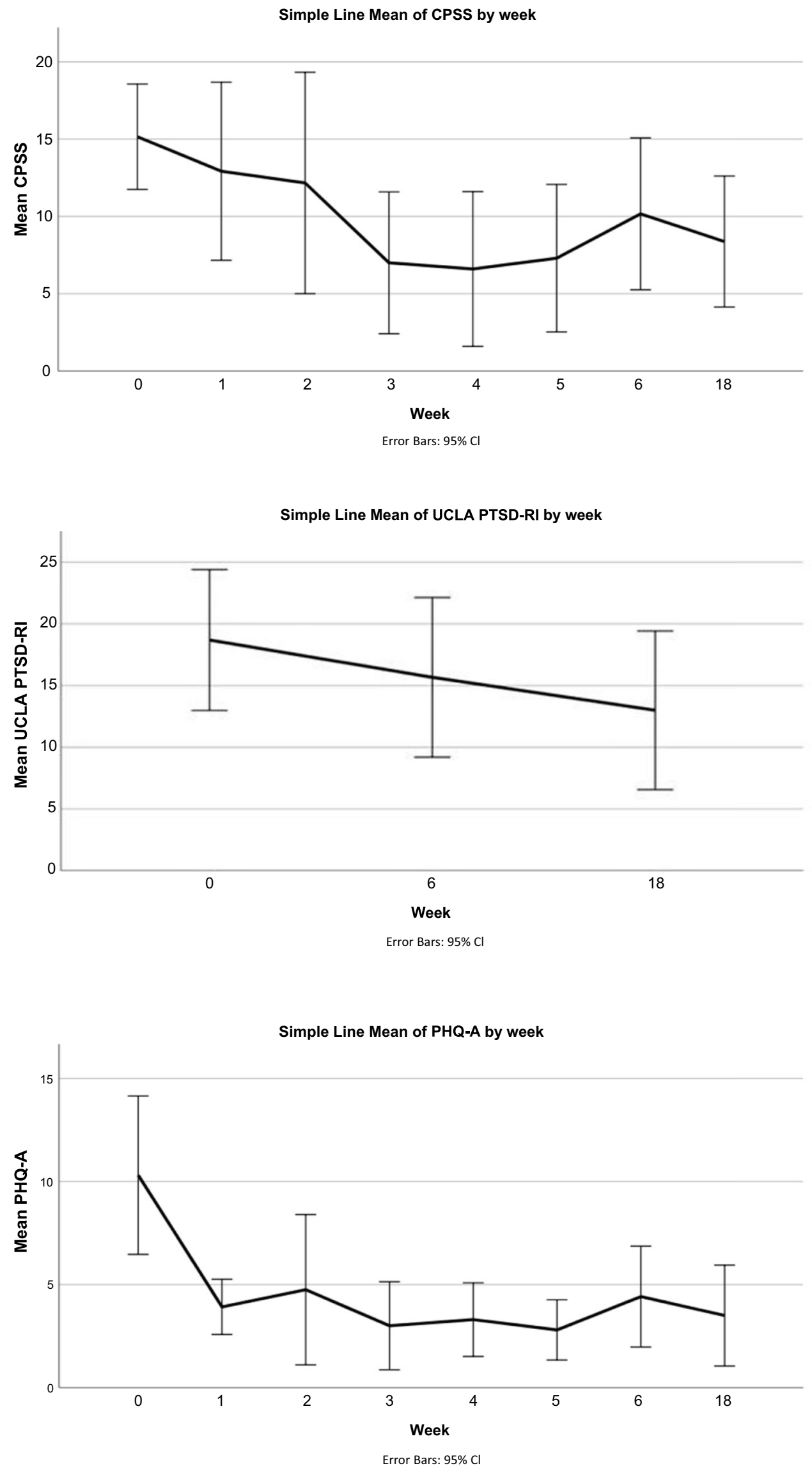